\title{
Spastic paraplegia, dysarthria, brachydactyly, and cone shaped epiphyses: confirmation of the Fitzsimmons syndrome
}

\author{
Raoul C M Hennekam
}

\begin{abstract}
A girl with slowly progressive difficulty in walking, dysarthria, growth retardation, brachydactyly, and cone shaped epiphyses is described. This constellation of symptoms was described in 1987 by Fitzsimmons and Guilbert. It probably represents a rare mendelian disorder of unknown cause.
\end{abstract}

( $\mathcal{F}$ Med Genet 1994;31:251-252)

In 1987, Fitzsimmons and Guilbert ${ }^{1}$ described in this Journal male uniovular twins with slowly progressive spastic paraplegia, dysarthria, brachydactyly, and cone shaped epiphyses. To the best of my knowledge no similar patients have been described since. A girl with the same constellation of symptoms is reported here to delineate this entity further.

\section{Case report}

The proband was the second child of healthy non-consanguineous parents. Two earlier pregnancies had ended in early spontaneous miscarriages. An older sister aged 13 years was healthy. Anthropometry gave normal results in the parents and the sib. Further family history was non-contributory. The mother denied the use of (possible) teratogenic drugs during pregnancy. At a gestational age of 38 weeks 1 day the proband was born weighing $1935 \mathrm{~g}$ (below the 3rd centile) and with a length of $47 \mathrm{~cm}$ (10th centile). The placenta was very small. Because of feeding problems she needed gavage feeding for five weeks. The neonatal period was otherwise uneventful. Her psychomotor development was normal except for her speech development: she first used words at 3.5 years of age, and later she received speech therapy because of indistinct speech. Because of her speech problems she attended a special school for children with hearing and speech deficits.

At the age of 4 years she was referred because of her small stature. Her height was $93.4 \mathrm{~cm}$ (below the 3 rd centile), arm span was $83.5 \mathrm{~cm}$, weight was $11.9 \mathrm{~kg}$ (below the $3 \mathrm{rd}$ centile), and head circumference was $48.1 \mathrm{~cm}$ (25th centile). She had a narrow face, a mildly prominent forehead, some midfacial hypoplasia, a highly arched palate, and irregularly placed teeth (fig 1). Her limbs were thin and short compared to her trunk. She had brachydactyly (total hand length was $1.5 \mathrm{~cm}$ below the 3rd centile) and broad thumbs (fig 2). Metacarpophalangeal pattern profile analysis confirmed the shortness of the metacarpals and phalanges, especially of the second middle phalanx and first distal phalanx. Her toes were short and her halluces broad (fig 2). At this age only mild tiptoeing was present.

At 8 years of age she was reinvestigated. Her height was $117 \cdot 2 \mathrm{~cm}$ (below the 3 rd centile), arm span $106 \mathrm{~cm}$, and sitting height $63.2 \mathrm{~cm}$. Her speech had improved, but was still indistinct and hypernasal. She had normal school achievements. She had developed a mild pectus excavatum, an increased lumbar lordosis, and she walked on her toes almost constantly. Orthopaedic examination failed to show the cause of her walking difficulties. Surprisingly,

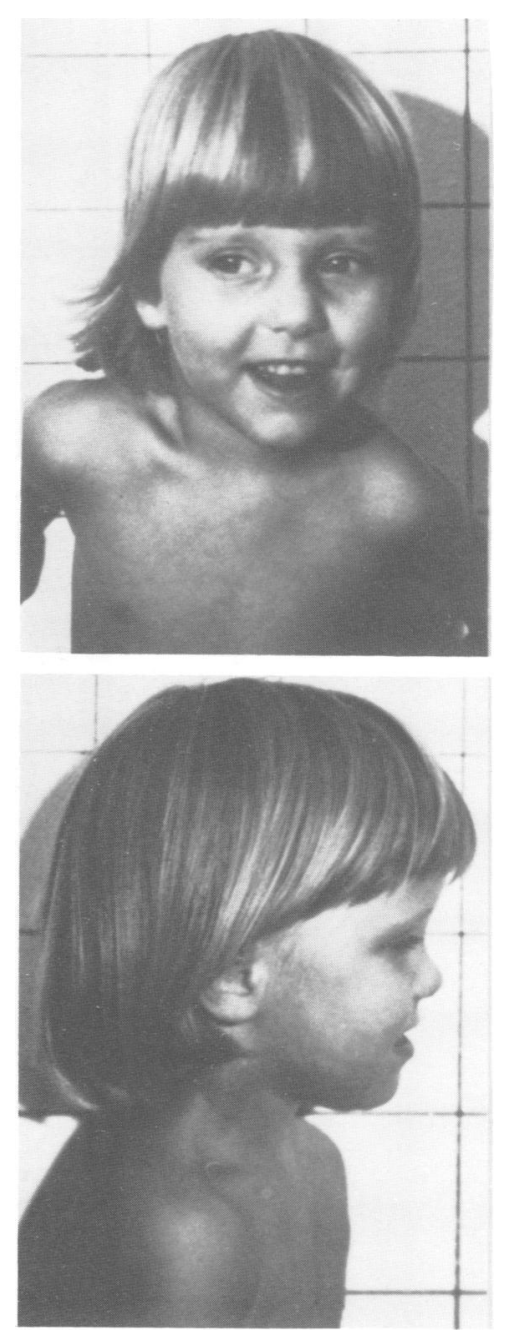

Figure 1 The proband aged 4 years. Note narrow face and mild midfacial hypoplasia. 

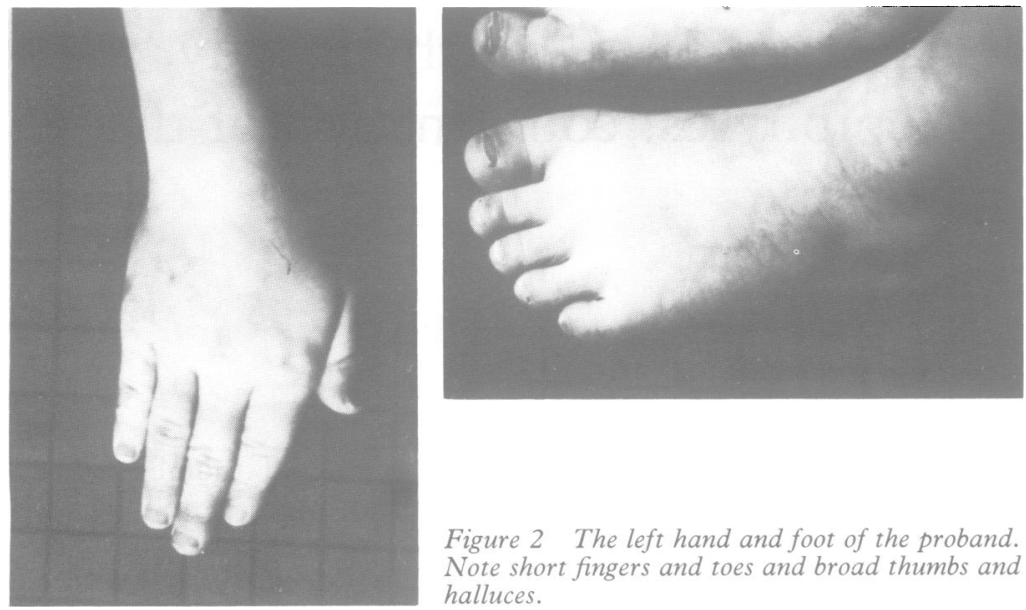

Figure 2 The left hand and foot of the proband. Note short fingers and toes and broad thumbs and halluces.

a child neurologist found only minimal indications of a neurological cause, despite extensive investigations including nerve conduction velocity and EMG studies. Only the ankle reflexes were pronounced. Spinal $x$ rays
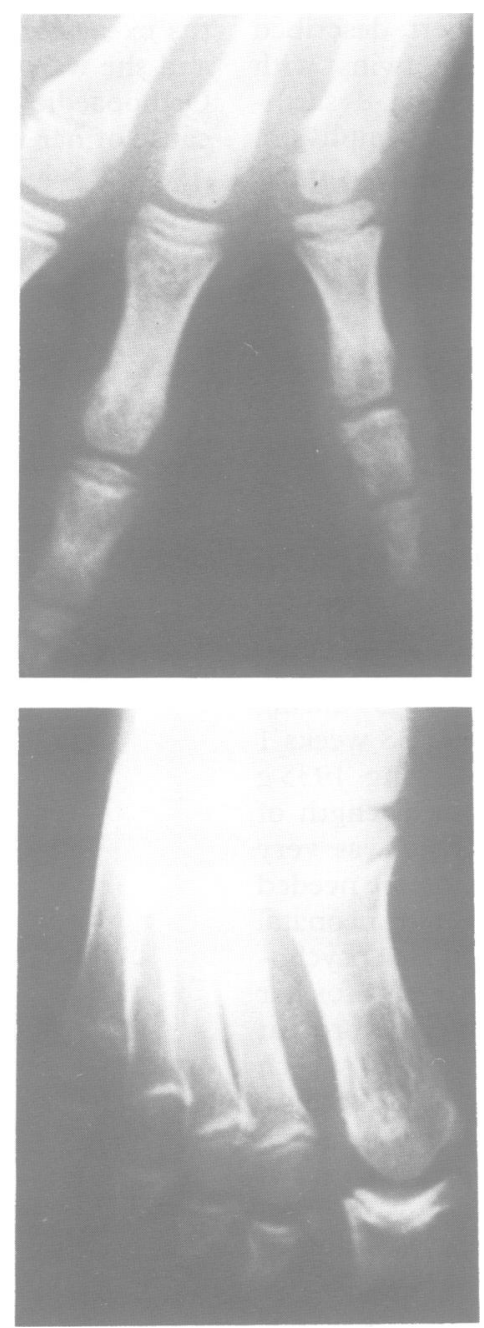

Figure $3 X$ rays of the hand and foot of the proband showing cone shaped epiphyses of the proximal fifth phalanx (above) and proximal first phalanx (below). Metacarpophalangeal pattern profile analysis in the proband showed a marked resemblance to the profiles found in the earlier described cases (correlation coefficients between proband and case $1 r=0.58$ $(p<0.01)$ and between proband and case $2 r=0.61$ $(p<0.01))$
Findings in the present patient compared to those reported by Fitzsimmons and Guilbert

\begin{tabular}{llll}
\hline & $\begin{array}{l}\text { Twin } \\
1^{1^{*}}\end{array}$ & $\begin{array}{l}\text { Twin } \\
2^{l^{*}}\end{array}$ & $\begin{array}{l}\text { Present } \\
\text { patient }\end{array}$ \\
\hline Prenatal growth deficiency & - & - & + \\
Postnatal growth deficiency (centile) & $3 \mathrm{rd}$ & $3 \mathrm{rd}$ & 3rd \\
Head circumference (centile) & $75 \mathrm{th}$ & $98 \mathrm{th}$ & $25 \mathrm{th}$ \\
Dysarthria & + & + & + \\
Progressive walking difficulties & + & + & + \\
Progressive spastic paraplegia & + & + & - \\
Mild midfacial hypoplasia & + & + & + \\
Sternal abnormality & car & car & exc \\
Brachydactyly & + & + & + \\
Broad thumbs/halluces & $+/+$ & $+/+$ & $+/+$ \\
Cone shaped epiphyses & & & \\
$\quad$ Hands & + & + & + \\
Feet & + & + & + \\
\hline
\end{tabular}

* Additional data provided by Dr I D Young.

+ car $=$ carinatum, exc $=$ excavatum.

showed absence of the normal widening of the interpeduncular distances, but a CT scan of the lumbar vertebral region gave normal results without any indication of stenosis of the vertebral canal. Additional investigations included a urinary metabolic screen, endocrine survey, cardiac and ophthalmological investigations, and karyotyping, all with normal results. A full skeletal survey showed cone shaped epiphyses of the proximal fifth phalanges of the hands and the proximal first phalanges of the feet (fig 3). The first rays of both hands and feet were broad. No other abnormalities were present.

\section{Discussion}

The findings in the present patient are compared to those present in the patients of Fitzsimmons and Guilbert ${ }^{1}$ in the table. The data from the 1987 publication were kindly amplified by Dr I D Young, who recently reinvestigated the twins. Their spasticity had increased considerably, to the extent that walking had become very difficult. Their dysarthria had remained unchanged. No other health problems were noted and mental status was completely normal in both. One of the twins had fathered three children, the eldest being 5 years of age. All enjoyed good general health and had normal muscle tone and normal mental development.

The main symptoms in the three patients are postnatal growth deficiency, progressive walking difficulties resulting in spastic paraplegia in the two oldest patients, dysarthria, brachydactyly, and cone shaped epiphyses in the hands and feet. Mental development is normal. The cause and pattern of inheritance remains uncertain, although single gene transmission seems likely.

Until more families are reported and the aetiology is clearer, the eponym Fitzsimmons syndrome is suggested.

I thank Dr Ian D Young (Nottingham) for his extensive efforts 1 thank Dr lan D Young to gather additional information about the patients from the original case report, and the pre
tion during this investigation.

1 Fitzsimmons JS, Guilbert PR. Spastic paraplegia associated with brachydactyly and cone shaped epiphyses. F Med Genet 1987;24:702-5. 